\title{
Optimising Cheese Brining Times
}

\author{
S. T. P. Psaltis ${ }^{1} \quad$ J. E. F. Green ${ }^{2} \quad$ T. W. Farrell ${ }^{3}$ \\ B. Lawson ${ }^{4}$ J. L. Simpson ${ }^{5}$
}

(Received 19 March 2015; revised 6 July 2016)

\begin{abstract}
In this article we detail the work conducted during MISG2014 on the brining of Gouda cheese for the Fonterra Cooperative Group. We consider three different mathematical models that aim to predict the salt content of cheese post-brining. The first is a diffusion model that accounts for the interstitial volume that is available for salt and water transport within the cheese. It predicts moisture content that agrees closely with data provided by Fonterra, and we show how modifications to the salt diffusivity and partial molar volume can improve the accuracy of the salt content predictions. The second model considers the moisture in the cheese to be in two phases - free moisture that contributes to the porosity of the cheese and is accessible to salt diffusion, and water that is bound by the cheese protein. The third model, referred to here as the salt-uptake model, is a reaction-diffusion model that considers salt being bound to the cheese matrix as it diffuses through the cheese.
\end{abstract}

http://journal.austms.org.au/ojs/index.php/ANZIAMJ/article/view/9430 gives this article, (c) Austral. Mathematical Soc. 2016. Published July 28, 2016, as part of the Proceedings of the 2014 Mathematics and Statistics in Industry Study Group. ISSN 1445-8810. (Print two pages per sheet of paper.) Copies of this article must not be made otherwise available on the internet; instead link directly to this URL for this article. 
More work is required on this model to be able to draw conclusions regarding the cheese brining process.

Keywords: cheese, brining, Gouda, mathematical modelling

\section{Contents}

1 Introduction

M58

2 Interstitial diffusion model

2.1 Governing equations . . . . . . . . . . . . . M63

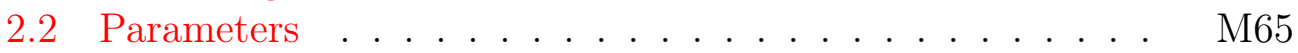

2.3 Results . . . . . . . . . . . . . . . . M66

3 The osmosis model of cheese brining. $\quad$ M74

3.1 The model . . . . . . . . . . . . . . . M76

3.2 Results . . . . . . . . . . . . . . . . . . . . . . . M79

3.3 Conclusions . . . . . . . . . . . . . . . . M85

4 Salt up-take model $\quad$ M87

4.1 Governing equations . . . . . . . . . . . . . . M87

4.2 Preliminary results . . . . . . . . . . . . . M88

5 Discussion

M90

References

M92

\section{Introduction}

Salt plays an important role in cheese, affecting the flavour, texture, moisture content and cooking properties. It also helps to regulate microbial activity. Salt content varies widely between cheese types, from around 4-6\% (by 
weight) in pickled types such as feta and Domiati, to $0.5-0.7 \%$ in others such as Emmenthal [9]. There are three main processes by which salt is added to cheese during production: dry salting, the addition of salt crystals to the curd pieces during manufacture (used in cheese such as cheddar); surface dry salting, where salt is added to the surface of the moulded curds (used in many types of blue cheeses); and brining, where the cheese is immersed in brine solution (used in cheeses such as Edam and Gouda). This article is concerned with this last process.

Fonterra runs the only brine cheese plant in the Southern Hemisphere, dissolving 750 tonnes of salt and 50 tonnes of calcium salts in a 3.5 million litre brine bath, to produce over 22,000 tonnes of brine salt cheese each year. Brine cheese is produced in a similar manner to dry salted cheese for the first few steps. Rennet and starters are added to vats of standardised and pasteurised milk which are then given time to set before being cut, washed and cooked to form curds and whey. The curd is separated from the whey, and then pumped to the top of towers where the curds knit together under their own weight. At the base of the towers, blocks of cheese are cut to be approximately $10 \mathrm{~kg}$. These blocks resemble pressed cottage cheese in appearance, and get loaded directly into moulds. These moulds then undergo pressing, under three different pressures, for approximately two hours during which time the whey is continuously removed from the cheese. After the pressing has finished the cheese is left (in the moulds) for approximately one hour to allow for the $\mathrm{pH}$ to decrease. At the end of this the cheese has knitted together into a solid block, but is still quite pliable and relatively easy to break (especially the corners). The cheese also cools during this time.

Once the cheese is in this stage it is removed from the moulds and conveyed into the brine baths. Plug samples are taken from near the centre of the cheese before going into the brine (a tool like an apple corer is stabbed into the cheese and all of the sample is analysed for gross composition and $\mathrm{pH}$ ). Once in the brine bath the cheese is allowed to float to its destination. Flow currents direct the cheese along the surface of the brine bath to cages that are being filled. The cages are multi-layered and are loaded from the bottom 
layer. Once the cage at a given layer is filled then that cage is submerged beneath the surface of the brine solution and another cage moves down to take its place until all cages are filled with cheese blocks and submerged in brine solution. The loading of the cages is done under the supervision of an operator; however, the spatial distribution of blocks in a given cage is not necessarily uniform. There are approximately 250 blocks of cheese per layer (cage). The brine is tested regularly for $\mathrm{pH}$ and salinity. The temperature of the bath is also monitored and is maintained to target levels through automated systems. The temperature, $\mathrm{pH}$ and salt concentration were found (during a recent trial) to be relatively constant (no statistically significant variations) throughout the entire brine bath.

Gouda cheese, one of the main types produced by Fonterra, takes approximately 48-55 hours to brine. Cheese samples are removed from blocks in the top layer of cages for testing from approximately two hours before the expected brining time onwards. When the salt content meets the required specification, the cages will begin to be unloaded. This is done using a first-in-last-out workflow and it takes about 40 minutes in total. Recent testing has shown that there is little difference between the gross composition of the blocks on the topmost and bottommost cages. After the blocks are removed from the brine solution they are washed, dried and vacuum packed to continue further ripening. The salt levels within the block of cheese affect the cheese quality during the ripening time; influencing the flavour and texture profile by controlling the breakdown of the protein and fat, as well as inhibiting micro-organisms (both the Starter and Non Starter Lactic Acid Bacteria). Thus, the salt content is of critical importance to the quality of the final product.

Currently, brining times are estimated based on cheese specification, the desired final product salt content, initial cheese moisture and manufacturing experience. Brine bath concentration and temperature are monitored over the entire brining period, while samples of cheese are analysed when the estimated brining time is approaching. If the cheese is left in the brine too long, then a hard skin or rind forms on the surface of the cheese which prevents (or at least, 
greatly diminishes) further absorption of salt. Moisture is expelled from the cheese as salt is taken up, and the higher the moisture content of the block, the more porous it is, resulting in improved salt infiltration. However, the relationship between moisture and final salt content is not well understood. The current prediction and monitoring routine is generally sufficient to ensure the cheese is manufactured within specification (with respect to salt content) and within predicted operating time-frames. However, if the expected brining times or salt uptake times do not adhere to the expected time-frames, the operation of the cheese plant can be severely impacted or the product be downgraded from the original specification.

The Study Group was asked to develop a tool to enable a more accurate prediction of brining times based on initial and desired final cheese composition and brine concentration, $\mathrm{pH}$ and temperature. A model that identifies the main variables and allows for the exploration of 'what if' scenarios on the effect of brining times would allow Fonterra to gain more control over the brining process. To this end the Study Group devised three different models, each of which are detailed in the following sections. Validation with experimental data and outcomes from numerical simulations for each of the models are also given and discussed.

\section{Interstitial diffusion model}

The structure of cheese is very complex, consisting of a protein matrix containing fat globules and cheese moisture that contains various dissolved substances. During brining, salt enters the cheese due to the osmotic pressure gradient between the cheese moisture and the brine. There is a corresponding loss of moisture from the cheese matrix; the quantity of water lost is generally about twice that of the salt gained [9]. Previous studies modelled salt and water transport in cheese as diffusive processes [15, e.g.]. However, whilst some used the familiar Fickian theory (with either constant or composition-dependent diffusion coefficients), others chose more complicated approaches, such as the 
Maxwell-Stefan theory [5, 15, e.g.]. Although these latter approaches give good agreement with experimental data, they contain a number of parameters that are difficult to measure in practice. Thus, the Study Group sought to take a simpler approach with fewer parameters.

An important experimental observation is that the effective diffusion coefficient for salt through cheese moisture is typically around $0.2 \mathrm{~cm}^{2}$ day ${ }^{-1}$ compared to $1.0 \mathrm{~cm}^{2}$ day $^{-1}$ for salt through pure water [9]. This is because salt is not able to diffuse effectively through the protein and fat globules in the cheese. We take this diffusion inhibition into account by introducing the concept of the interstitial (or pore) volume of the cheese. The interstitial volume is the fraction of the cheese volume through which salt and water transport occurs. We postulate that the total interstitial volume is made up of a fraction occupied by salt and a fraction occupied by moisture. As salt and water (moisture) are transported into and out of the cheese block the interstitial volume fraction can vary (in space and time) due to a difference in the molar volumes and the local concentrations of salt and water. Furthermore, this variation in interstitial volume fraction in turn influences the transport of salt and water within the cheese. Low interstitial volumes correspond to tortuous transport pathways that significantly impede the movement of salt and water, whereas high interstitial volumes facilitate the movement of these species. We have considered that a change in local interstitial volume does not result in a change in the total volume of the cheese (i.e., a swelling or shrinking of the cheese block). Rather we assume that the dimensions of the cheese block remain unchanged during brining even though locally the cheese protein matrix may compress or stretch to accommodate a change in the local interstitial volume. We reconcile this assumption by noting that a complex interaction between the salt and water species and the protein matrix, reported by Mandl et al. [12], may lead to (local) topological distortions of the matrix depending on the salt concentration, and that Fonterra observe little variation in the volume of the cheese block before and after brining [7].

Using the above assumptions, Section 2.1 develops a Fickian diffusion model. 
Figure 1: Simplified representation of a block of cheese.

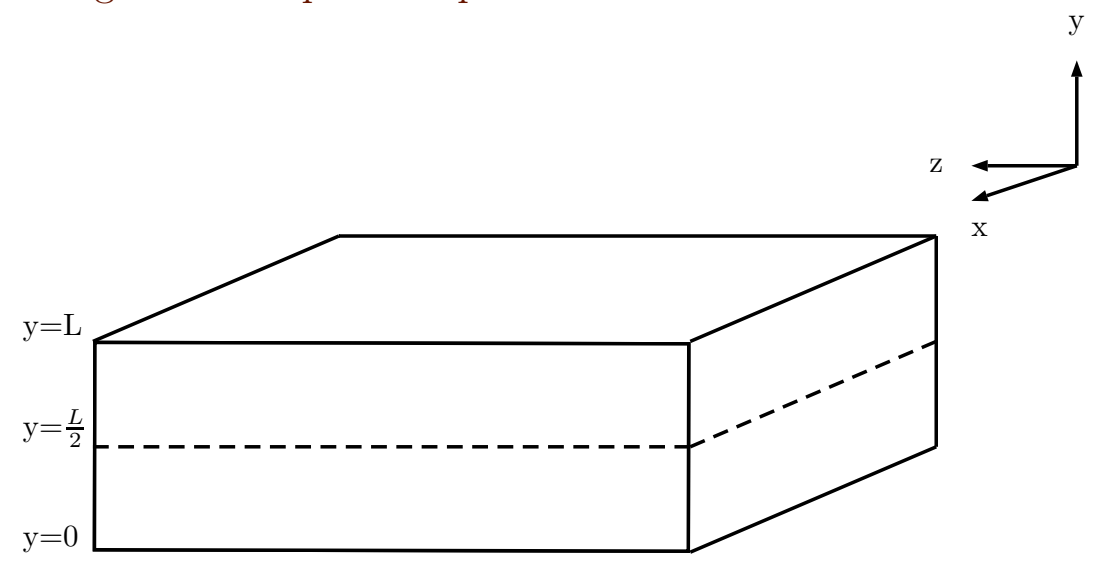

\subsection{Governing equations}

We consider a cuboidal block of cheese with orientation as shown in Figure 1. Typically, these blocks have dimensions that are significantly larger in the $x$ and $z$-directions than the $y$-direction (typically $\Delta x=27 \mathrm{~cm}, \Delta y=10 \mathrm{~cm}$ and $\Delta z=35 \mathrm{~cm}[7])$. In addition, as noted above, the spatial distribution of salt within the brine bath is measured to be essentially constant, and thus most of the blocks are subject to similar salt concentrations on their lower $(y=0)$ and upper $(y=L)$ surfaces. Given these observations we develop a one-dimensional transport model (in the $y$-dimension) that is assumed to be symmetric about the midplane $\mathrm{y}=\mathrm{L} / 2$.

Our aim is to predict the salt, $\mathrm{C}$, and water, $\mathrm{W}$, concentrations $\left(\mathrm{kg} \mathrm{m}^{-3}\right)$ of the block at position $y$ and time $t$. We denote the interstitial volume fraction of the cheese, as described above, by $\varepsilon$. Assuming that salt and water 
transport occur by diffusion, our governing equations are then

$$
\begin{aligned}
& \frac{\partial(\varepsilon \mathrm{C})}{\partial \mathrm{t}}=\nabla \cdot\left[\mathrm{D}_{\mathrm{C}} \nabla(\varepsilon \mathrm{C})\right], \\
& \frac{\partial(\varepsilon \mathrm{W})}{\partial \mathrm{t}}=\nabla \cdot\left[\mathrm{D}_{W} \nabla(\varepsilon \mathrm{W})\right],
\end{aligned}
$$

for salt and water, respectively. The effective diffusion coefficients for each species, $D_{C}$ and $D_{W}$, are assumed to depend on the interstitial volume fraction $\mathcal{E}$. As noted above, this is to account for as the pore volume decreases, the transport pathway becomes more tortuous and the diffusion of species is hindered. There have been many studies on the effects of porous microstructure on diffusion and various theories are available to determine this. We adopt a Bruggeman relation [3],

$$
\begin{aligned}
& D_{C}(y, t)=D_{C}^{\infty} \varepsilon^{3 / 2} \\
& D_{W}(y, t)=D_{W}^{\infty} \varepsilon^{3 / 2},
\end{aligned}
$$

where $D_{C}^{\infty}$ is the binary diffusivity of salt $(\mathrm{NaCl})$ in water and $\mathrm{D}_{W}^{\infty}$ is the tracer diffusivity of water, both in the absence of porous structure, and are here assumed constant. The Bruggeman relation is an analytic expression originally derived for predicting effective dispersion in beds of spherical particles of differing sizes. It is used here in the absence of any detailed knowledge of the matrix structure of cheese.

The interstitial space itself is assumed to be filled by either salt or moisture, and hence we set

$$
\varepsilon(y, t)=\bar{v}_{W} \frac{W}{M_{W}}+\bar{v}_{C} \frac{C}{M_{C}},
$$

where $\bar{v}_{W}$ and $\bar{v}_{C}$ are the partial molar volumes of water and salt in brine solution, respectively (here assumed to be constant) and $M_{W}$ and $M_{C}$ are the molar masses of water and salt $(\mathrm{NaCl})$, respectively. The partial molar volume, $\bar{v}_{i}$, of component $i$ in a mixture describes the change to the total volume of the mixture per mole of component $i$ added to the mixture at a constant pressure and temperature [1]. Given this, we see that the first 
and second terms on the right-hand side in expression (5) represent the local volume fractions of water and salt, respectively, throughout the cheese block.

In order to close our system of model equations (1)-(5), appropriate boundary and initial conditions are required. We assume that the cheese block initially contains no salt and that the initial moisture content is spatially uniform, with $W=W_{i}$. Furthermore, the brine in the bath, in which the cheese is immersed, is assumed to be maintained at a constant salinity. Our initial and boundary conditions are thus

$$
\begin{aligned}
& C=0, \quad W=W_{i} \quad \text { at } t=0, \\
& C=C_{b}, \quad W=W_{b} \quad \text { at } y=0, \\
& \frac{\partial(\varepsilon C)}{\partial y}=\frac{\partial(\varepsilon W)}{\partial y}=0 \quad \text { at } y=\frac{L}{2},
\end{aligned}
$$

where $C_{b}$ and $W_{b}$ are the concentrations of salt and water, respectively, in the brine bath.

\subsection{Parameters}

Table 1 lists the parameter values used in the interstitial diffusion model and the associated references from which these values were sourced. Since we assume that only water is present initially in the interstitial volume of the cheese, then $W_{i}$ is the density of pure water. Furthermore, $\bar{v}_{W}$ was calculated on the basis that the cheese block has an initial moisture content of $v_{0} \times 100 \%$ (wt) (determined from data [7]), assuming that the dimensions of the block are $10 \times 27 \times 35(\mathrm{~cm})$ and again recalling that initially in the interstitial volume of the cheese is due only to the presence of water. Noting these and equation (5) we then set

$$
\bar{v}_{W}=\frac{v_{0} M_{W} M_{T}}{W_{i}^{2} V_{T}},
$$

where $M_{T}(\mathrm{~kg})$ is the initial mass of the cheese block and $V_{T}\left(m^{3}\right)$ is the total volume of the cheese block. 
Table 1: Parameter values used in the interstitial diffusion model.

\begin{tabular}{lll}
\hline Parameter & Value & Reference \\
\hline $\mathrm{C}_{\mathrm{b}}$ & $250\left(\mathrm{~kg} \cdot \mathrm{m}^{-3}\right)$ & {$[7]$} \\
$\mathrm{D}_{\mathrm{C}}^{\infty}$ & $1.5756 \times 10^{-9}\left(\mathrm{~m}^{2} \cdot \mathrm{s}^{-1}\right)$ & {$[6]$} \\
$\mathrm{D}_{\mathrm{W}}^{\infty}$ & $2.265 \times 10^{-9}\left(\mathrm{~m}^{2} \cdot \mathrm{s}^{-1}\right)$ & {$[17]$} \\
$\mathrm{L}$ & $0.1(\mathrm{~m})$ & {$[7]$} \\
$\mathrm{M}_{\mathrm{C}}$ & $0.06\left(\mathrm{~kg} \cdot \mathrm{mol}^{-1}\right)$ & {$[2]$} \\
$\mathrm{M}_{W}$ & $0.018\left(\mathrm{~kg} \cdot \mathrm{mol}^{-1}\right)$ & {$[2]$} \\
$\bar{v}_{\mathrm{C}}$ & $22 \times 10^{-6}\left(\mathrm{~m}^{3} \cdot \mathrm{mol}^{-1}\right)$ & Calc. \\
$\bar{v}_{W}$ & $7.3 \times 10^{-6}\left(\mathrm{~m}^{3} \cdot \mathrm{mol}^{-1}\right)$ & Calc. \\
$W_{\mathrm{b}}$ & $750\left(\mathrm{~kg} \cdot \mathrm{m}^{-3}\right)$ & {$[7]$} \\
$W_{\mathrm{i}}$ & $1000\left(\mathrm{~kg} \cdot \mathrm{m}^{-3}\right)$ & Calc. \\
\hline
\end{tabular}

\section{$2.3 \quad$ Results}

Equations (1)-(5) were discretised spatially to obtain a system of timedependent ordinary differential equations (ODEs). The numerical solution of these ODEs was implemented in MATLAB [13] using ode15i and were solved subject to initial and boundary conditions (6)-(8). We parameterised the model with diffusivity values from Table 1 and calculated partial molar volumes, and the brine conditions provided by Fonterra were utilised for our boundary conditions. Furthermore, we estimated the initial interstitial volume using data from Fonterra for the initial moisture content of cheese. Fonterra provided a range of data regarding initial moisture content and brining time for Gouda cheese. The data were collected under normal operating procedure, with measurements taken from blocks of cheese that entered and exited the brine bath at the same times (to see if any variation existed between blocks). Due to commercial sensitivity, actual manufacturing results are not able to be published. We executed our simulation using the initial moisture content for the specified brining time, and upon converting our one-dimensional results to align with a cheese block found good agreement with the final moisture content data, as shown by the relative error in Table 2. However, there was 
Table 2: Predicted final salt and moisture levels from Model 1, with relative errors compared to measured values from Fonterra.

\begin{tabular}{lllll}
\hline $\begin{array}{l}\text { Brine } \\
\text { time } \\
\text { (hours) }\end{array}$ & $\begin{array}{l}\text { Predicted } \\
\text { moisture } \%\end{array}$ & $\begin{array}{l}\text { Predicted } \\
\text { salt \% }\end{array}$ & $\begin{array}{l}\text { Moisture } \\
\text { Relative } \\
\text { Error } \%\end{array}$ & $\begin{array}{l}\text { Salt Rel- } \\
\text { ative Er- } \\
\text { ror \% }\end{array}$ \\
\hline 49.50 & 40.38 & 2.10 & 0.05 & 30 \\
49.50 & 40.45 & 2.11 & 0.37 & 28 \\
50.25 & 40.16 & 2.10 & 0.64 & 44 \\
50.25 & 40.24 & 2.11 & 0.10 & 44 \\
51.30 & 40.03 & 2.12 & 0.32 & 43 \\
51.30 & 40.31 & 2.14 & 0.40 & 39 \\
58.83 & 39.65 & 2.25 & 1.43 & 50 \\
58.83 & 39.13 & 2.21 & 0.10 & 39 \\
63.28 & 39.92 & 2.37 & 2.44 & 38 \\
63.28 & 40.51 & 2.43 & 0.25 & 44 \\
\hline
\end{tabular}

significant error in the predicted salt content, in that our model consistently overpredicted the amount of salt taken up by the cheese. This indicates that the rate of salt diffusion into the cheese is too high in our model.

Therefore, it is useful to ascertain how the rate of salt diffusion can be modified to reduce the predicted salt content of the cheese after brining. We considered two means of reducing the rate of salt diffusion into the cheese. These are: modification of the salt partial molar volume, $\bar{v}_{\mathrm{C}}$, as this will affect how the interstitial volume changes as salt diffuses into the cheese, and the salt diffusivity, $\mathrm{D}_{\mathrm{C}}^{\infty}$, as this governs how quickly salt is transported according to a concentration gradient. There are other means of modifying the interstitial volume, such as considering water to be in both bound and free states where only the free water contributes to the volume available for salt transport.

Firstly, $\bar{v}_{\mathrm{C}}$ has been reduced by $25 \%$ of the value given in Table 1 and our simulations run for the initial moisture and brining times given in Table 2. Table 3 shows that the relative error in the predicted salt content is reduced, 
Table 3: Predicted moisture and salt content with absolute relative errors in predicted moisture and salt levels from Model 1, with $\bar{v}_{\mathrm{C}}$ reduced by $25 \%$.

\begin{tabular}{lllll}
\hline $\begin{array}{l}\text { Brine } \\
\text { time } \\
\text { (hours) }\end{array}$ & $\begin{array}{l}\text { Predicted } \\
\text { Moisture \% }\end{array}$ & $\begin{array}{l}\text { Predicted } \\
\text { Salt \% }\end{array}$ & $\begin{array}{l}\text { Moisture } \\
\text { Relative } \\
\text { Error \% }\end{array}$ & $\begin{array}{l}\text { Salt Rel- } \\
\text { ative Er- } \\
\text { ror \% }\end{array}$ \\
\hline 49.50 & 40.07 & 1.95 & 0.72 & 20 \\
49.50 & 40.14 & 1.95 & 1.14 & 18 \\
50.25 & 39.85 & 1.95 & 1.41 & 33 \\
50.25 & 39.92 & 1.95 & 0.88 & 33 \\
51.30 & 39.71 & 1.96 & 1.11 & 32 \\
51.30 & 39.99 & 1.98 & 0.40 & 29 \\
58.83 & 39.31 & 2.08 & 0.57 & 39 \\
58.83 & 38.80 & 2.04 & 0.75 & 28 \\
63.28 & 39.57 & 2.20 & 3.29 & 28 \\
63.28 & 40.15 & 2.25 & 1.12 & 33 \\
\hline
\end{tabular}

Table 4: Predicted moisture and salt content with absolute relative errors in predicted moisture and salt levels from Model 1, with $\mathrm{D}_{\mathrm{C}}^{\infty}$ reduced by $25 \%$.

\begin{tabular}{lllll}
\hline $\begin{array}{l}\text { Brine } \\
\text { time } \\
\text { (hours) }\end{array}$ & $\begin{array}{l}\text { Predicted } \\
\text { Moisture \% }\end{array}$ & $\begin{array}{l}\text { Predicted } \\
\text { Salt \% }\end{array}$ & $\begin{array}{l}\text { Moisture } \\
\text { Relative } \\
\text { Error \% }\end{array}$ & $\begin{array}{l}\text { Salt Rel- } \\
\text { ative Er- } \\
\text { ror \% }\end{array}$ \\
\hline 49.50 & 40.39 & 1.81 & 0.07 & 12 \\
49.50 & 40.46 & 1.82 & 0.35 & 10 \\
50.25 & 40.17 & 1.81 & 0.61 & 24 \\
50.25 & 40.25 & 1.82 & 0.08 & 24 \\
51.30 & 40.04 & 1.83 & 0.30 & 24 \\
51.30 & 40.32 & 1.85 & 0.42 & 20 \\
58.83 & 39.66 & 1.94 & 1.46 & 30 \\
58.83 & 39.14 & 1.90 & 0.14 & 20 \\
63.28 & 39.94 & 2.05 & 2.41 & 20 \\
63.28 & 40.52 & 2.10 & 0.22 & 24 \\
\hline
\end{tabular}


Table 5: Predicted moisture and salt content with absolute relative errors in predicted moisture and salt levels from Model 1 , with $\bar{v}_{\mathrm{C}}$ and $\mathrm{D}_{\mathrm{C}}^{\infty}$ reduced by $25 \%$.

\begin{tabular}{lllll}
\hline $\begin{array}{l}\text { Brine } \\
\text { time } \\
\text { (hours) }\end{array}$ & $\begin{array}{l}\text { Predicted } \\
\text { Moisture \% }\end{array}$ & $\begin{array}{l}\text { Predicted } \\
\text { Salt \% }\end{array}$ & $\begin{array}{l}\text { Moisture } \\
\text { Relative } \\
\text { Error \% }\end{array}$ & $\begin{array}{l}\text { Salt Rel- } \\
\text { ative Er- } \\
\text { ror \% }\end{array}$ \\
\hline 49.50 & 40.08 & 1.68 & 0.70 & 4 \\
49.50 & 40.14 & 1.68 & 1.12 & 2 \\
50.25 & 39.86 & 1.68 & 1.39 & 15 \\
50.25 & 39.93 & 1.68 & 0.86 & 14 \\
51.30 & 39.72 & 1.69 & 1.09 & 14 \\
51.30 & 40.00 & 1.71 & 0.38 & 11 \\
58.83 & 39.32 & 1.79 & 0.59 & 20 \\
58.83 & 38.81 & 1.76 & 0.73 & 10 \\
63.28 & 39.58 & 1.89 & 3.27 & 10 \\
63.28 & 40.16 & 1.94 & 1.10 & 15 \\
\hline
\end{tabular}

and that less salt has been taken up by the cheese due to a decrease in the available pore space for salt diffusion.

Next, we consider the effect that a reduction in $\mathrm{D}_{\mathrm{C}}^{\infty}$ has on the predicted salt content. This is equivalent to introducing a tortuosity into equation (3) to further take into account the pore structure of the cheese. By reducing the diffusivity used in equation (3) by $25 \%$, we obtain approximately half the error in the predicted salt content, as given in Table 4. Due to the decreased diffusivity, for a given concentration gradient less salt will enter the cheese for a given brining time.

Reducing $\bar{v}_{\mathrm{C}}$ and $\mathrm{D}_{\mathrm{C}}^{\infty}$ individually by $25 \%$ has been shown to reduce the salt uptake predicted from the model. By combining the reduction in both $\bar{v}_{\mathrm{C}}$ and $D_{C}^{\infty}$ the error in predicted salt content is reduced further, as shown in Table 5. Noting that the error in the predicted moisture content remains low, a more accurate estimation of $\bar{v}_{\mathrm{C}}$ may lead to more accurate prediction 
Figure 2: Spatial profiles of salt density, water density and porosity after 63.28 hours brining time, obtained using the model composed of equations (1)(9). Initial moisture content is $43.43 \%$.
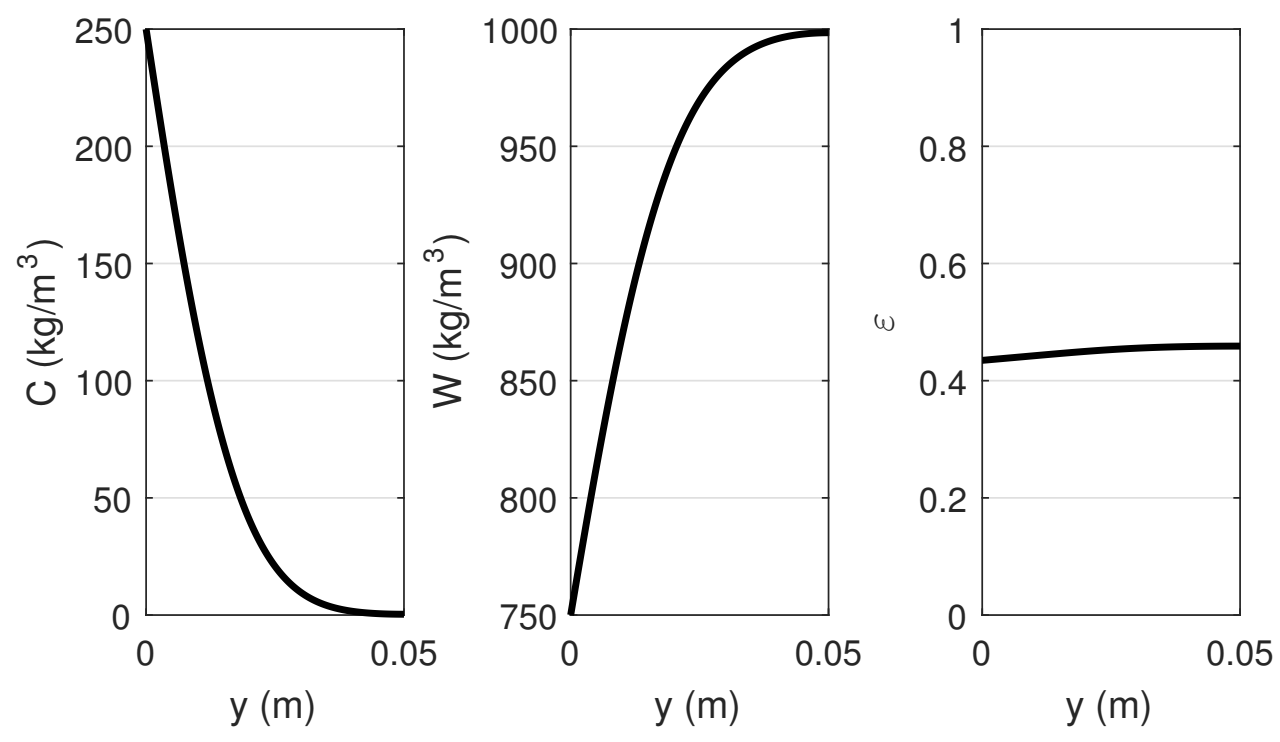

of salt content after brining of Gouda cheese. Furthermore, the use of the Bruggeman relations (equations (3) and (4)) may not give a realistic model of the diffusion coefficients within the cheese matrix and the use of more accurate diffusivities may lead to a more accurate prediction of the salt content.

Figure 2 shows the spatial profiles for salt and water densities and porosity at the end of the brining time as predicted by our model. There is a large uptake of salt at the boundary of the cheese, with salt diffusing towards the centre. A corresponding decrease in the density of water found within the interstitial volume of the cheese is also shown, as the water is displaced as the salt enters the cheese. As the salt diffuses into the cheese there is a 'swelling' of the cheese matrix due to the difference in size of the salt and water molecules, causing a reduction in the cheese interstitial volume. 
The results shown in Figure 2 are consistent with data from Geurts, Walstra and Mulder [8], and Messens, Dewettinck and Huyghebaert [14], that show a high peak in salt concentration near the surface of the cheese and a reduced water content. This is also confirmed by spatial data provided by Fonterra. Figure 3 shows the spatial salt and moisture content data provided by Fonterra. This figure represents an $x z$-view of a cheese block, whereas our one-dimensional model considers transport in the shorter $y$-direction. These spatial data have been measured by dividing a cheese block into 32 sub-blocks, homogenising each sub-block and calculating their salt and moisture content using near infrared (NIR) techniques. We attempted to quantify our model results with the spatial data provided by Fonterra; however, due to limitations in measurement ability, operational constraints and the one-dimensional nature of our model, a quantitative comparison could not be performed.

Before brining, the salt content of the cheese is approximately $0.12 \%$ due to the naturally occurring salt found in the cheese ingredients [7]. This is not reflected in Figure 3 as the NIR equipment used by Fonterra is unable to measure salt content below approximately 1\%. Figure 3 shows that the salt content of the cheese after brining is highest at the cheese boundaries and in particular at the corners where the greatest surface area of cheese will be exposed to the brine solution. This qualitatively confirms the salt behaviour that is predicted by our model, whereby the highest salt concentration occurs at the boundary. Conversely, we see that the majority of water is lost from the edges of the cheese during brining. This is also in agreement with the predictions of the model presented in Section 2.

Figure 4 shows the effect of the initial moisture content (for a fixed brining time) and the brining time (for a fixed initial moisture content) on the final salt content of the cheese. Figure 4 shows that the salt content is more greatly affected by the moisture content of the cheese, with a higher initial moisture content leading to greater salt uptake. This is because the salt diffuses into the cheese through the moisture, and the level of moisture is directly related to the volume available for salt uptake. Figure 4(b) shows that the rate of salt uptake decreases with increasing brining times. This is because as the salt is 
Figure 3: Data obtained from a cheese block brined for approximately 48 hours [7], showing prebrine (left) and postbrine (right) percent weight salt and moisture content.
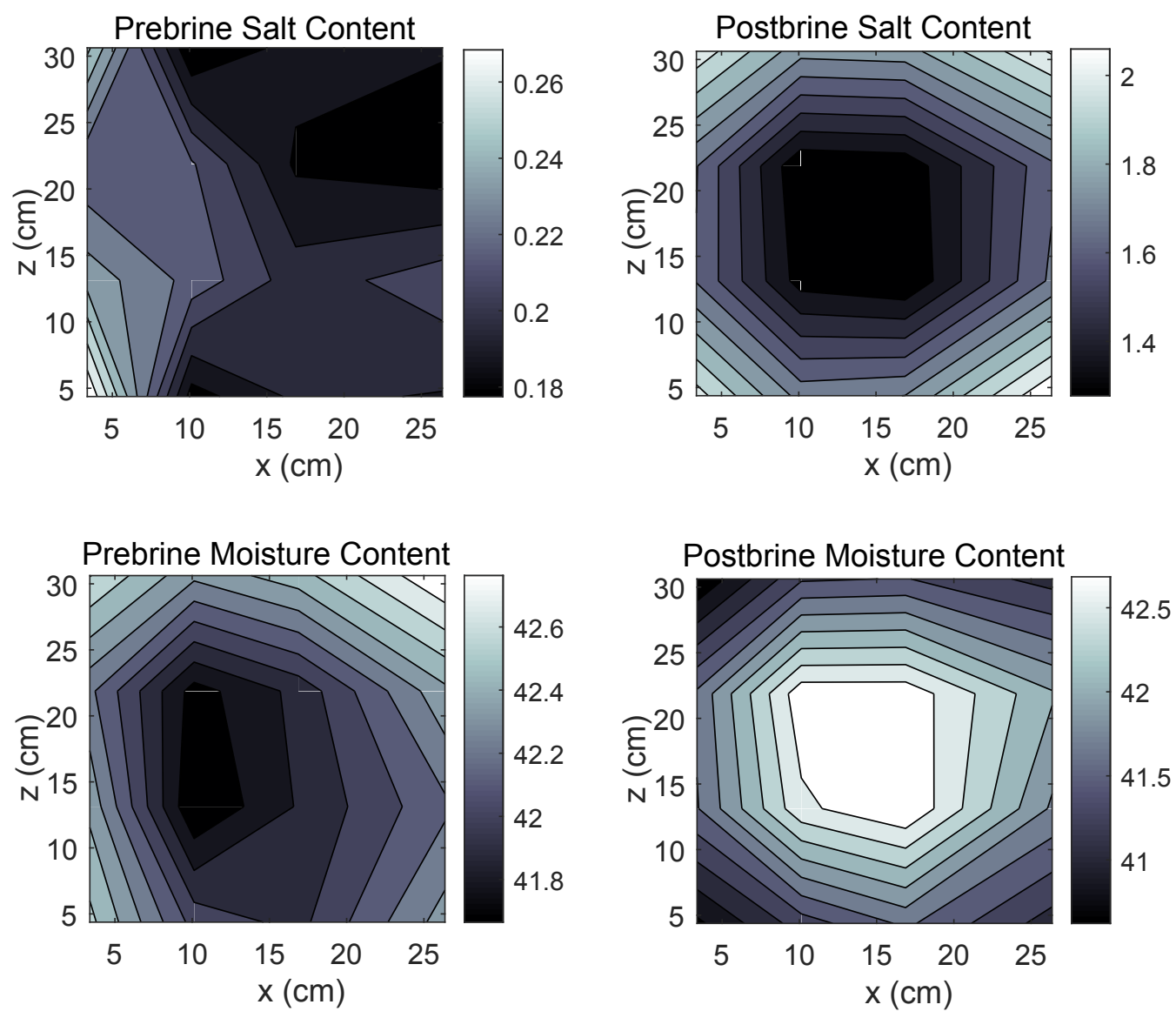
Figure 4: Effect of the initial moisture content and brining time on the final salt content. (a) A range of initial moisture content for a fixed period (20 hours) in brine solution. (b) An initial moisture content of $50 \%$ for a range of brining times.
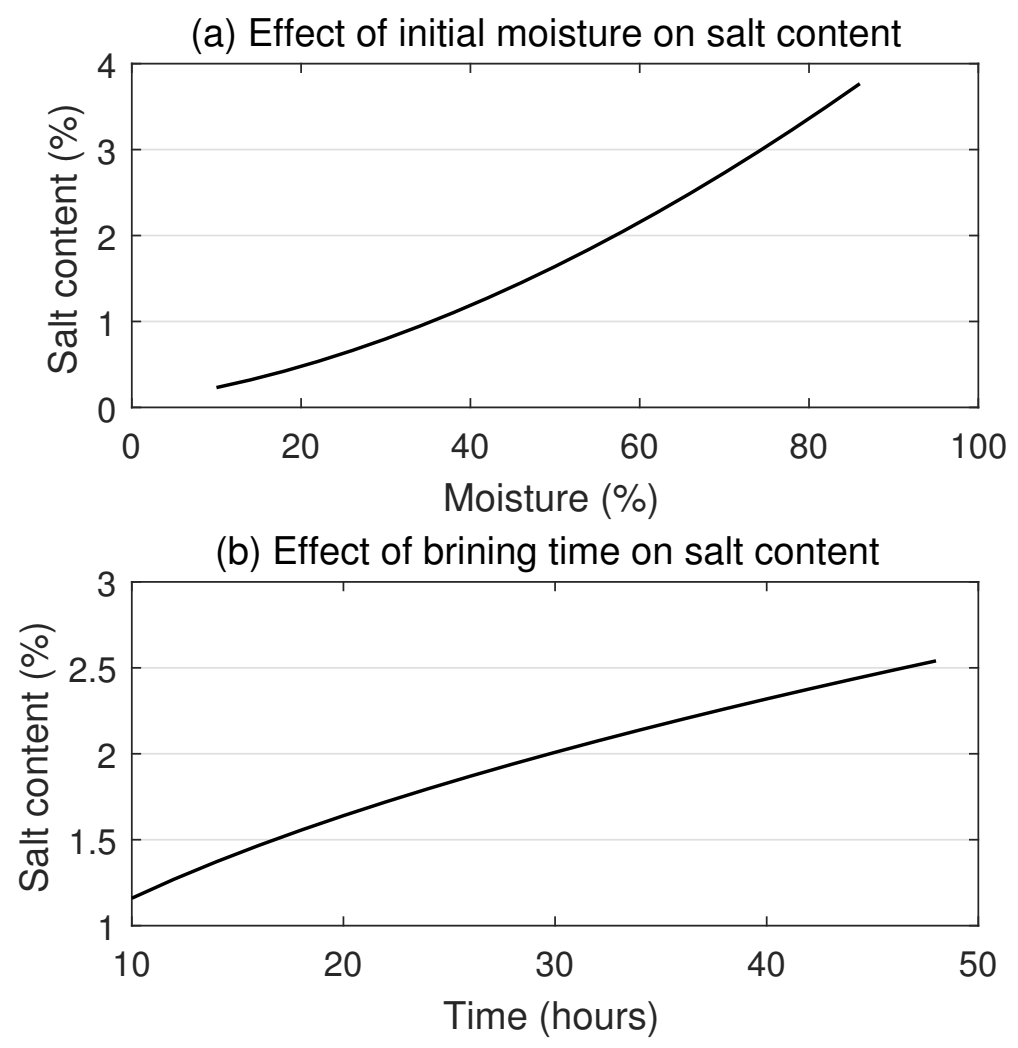
taken up by the cheese, the available volume reduces, thereby decreasing the ability of salt to diffuse into the cheese.

\section{The osmosis model of cheese brining.}

An alternative to the interstitial diffusion model presented in Section 2 was developed by a team within the main workshop group. This model is termed the osmosis model.

Brining affects the cheese by allowing salty water to leach into the cheese matrix via its porous network. The cheese matrix consists of impermeable fat globules and protein molecules, with the moisture occupying the negative space between them resulting in pores that allow transport, but also less accessible 'pockets' of water (Figure 5). When salty water leaches into the cheese, the difference in salt concentration creates osmotic pressure which draws out the moisture from these pockets, leading to the well known 'sweating' effect that comes from salting a food.

The process of brining a cheese brings moisture in the cheese matrix into contact with salted water, allowing sodium and chloride ions present in the brining mixture to diffuse into the cheese via the porous network offered by its moisture. However, as salt is absorbed by the cheese, the concentration difference in sodium and chloride ions also causes water to escape the cheese in order to restore osmotic pressure equilibrium [9]. Not all moisture in cheese is a part of the porous network and hence 'accessible' to salt, because some is bound by the protein, and this prompts the osmosis model to consider two types of moisture comprising the total moisture content of the cheese, namely free moisture that contributes to the porosity of the cheese, $\varepsilon$, and bound water that does not, $w$ :

$$
W=\varepsilon+w .
$$

Equating the pore volume fraction $\varepsilon$ with the weight fraction of pore water requires the assumption that the density of the cheese moisture in the porous 
Figure 5: Schematic of osmosis model showing the porous structure of the cheese block. The inset figure shows the displacement of water due to salt absorption and subsequent contraction of the pore space.
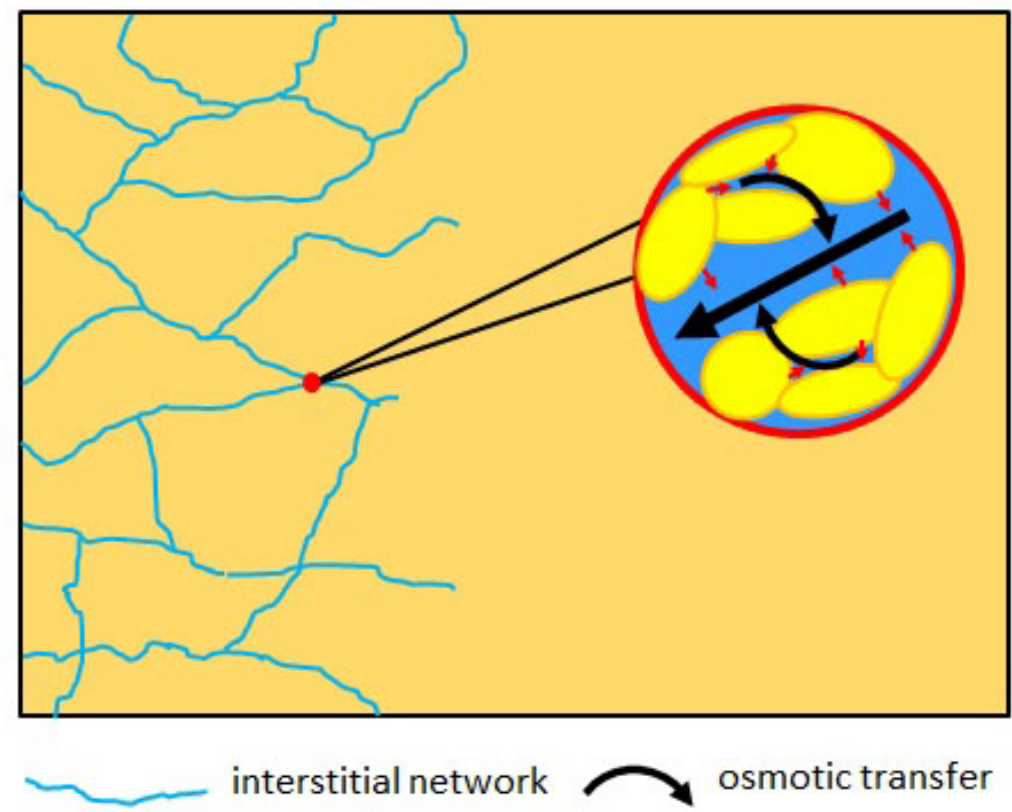

osmotic transfer

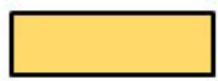

cheese block

salt impermeables

interstitial contraction 
network is approximately one.

\subsection{The model}

Defining moisture according to equation (10) allows the osmosis of the bound water, which is immobile when not being leached into the porous network, to be modelled separately. This effect is modelled here by allowing bound water to be 'consumed' by osmotic pressure until the amount of bound water present reaches a value which suggests an osmotic pressure equilibrium is achieved. This amount of bound water depends on both the concentration of salt in the pore moisture which causes this effect, and on the amount of pore water present. Defining the rate of this osmotic effect as $\mu$, the equation for changes in the bound water over time is thus

$$
\frac{\partial w}{\partial t}=\mu\left(w_{i}-k_{1} \varepsilon C-w\right) w
$$

where $w_{i}$ is the initial concentration of bound water present in the cheese matrix (or equivalently, the equilibrium point when $\mathrm{C}=0$ ).

The leaching of bound water also causes a 'shrinkage' effect in the cheese matrix that reduces the local pore space. Thus the porosity, $\varepsilon$, depends on the value of $w$. If the movement of free water outside of these physical changes in cheese structure is considered negligible, then the amount of present free water is simply determined by the available amount of pore space, and thus the functional dependence

$$
\varepsilon=f(w)
$$

provides the amount of free moisture present directly. This assumption is acceptable because the diffusion coefficient for moisture through the cheese matrix is very small [15], and the convective flow of water out of the cheese does not have much impact on salt transport during brining [16].

The diffusion of the salt into the cheese is represented simply by treating salt as diffusing through the moisture in the pore network but at an impeded 
rate due to tortuosity effects [8]. The dependence of the diffusion coefficient on physical factors means that it is not homogeneous throughout a block of cheese, due to the aforementioned changes that take place in response to the loss of bound moisture. This is evidenced by calculated diffusion coefficients which show decreased values in regions with a lower moisture content [15]. Thus the equation for the salt-in-moisture concentration $\mathrm{C}$ is

$$
\frac{\partial \mathrm{C}}{\partial \mathrm{t}}=\nabla[\mathrm{D}(\varepsilon) \nabla \mathrm{C}],
$$

with $\mathrm{D}(\varepsilon)$ a monotonically increasing function that captures how the diffusivity changes in response to the changes in porosity arising due to moisture loss.

The cheese is considered here as a one-dimensional solid, just as it was in the interstitial diffusion model. This choice simplifies the equations to be solved, but also allows for better comparison with experimental data, which typically uses blocks of cheese which are waxed on all but one side in order to localise salt seepage to one surface $[11,10]$. In the one-dimensional problem, the domain is taken as ranging across half the block of cheese, with one end $(y=0)$ being directly exposed to the brining solution and thus experiencing a fixed salt concentration while the other end $(y=L / 2)$ is assigned a noflux condition. The no-flux condition is indicative of a point sufficiently far away from the surface exposed to brine (because salt and moisture behaviour asymptote to their initial conditions deep inside the cheese) [11], or simply being halfway through the cheese and hence representing a point of symmetry (in the case where the opposite side is presumably also unwaxed). The initial salt-in-moisture content of the cheese is taken as zero, except at the boundary which is directly exposed to the brine, which naturally has a salt-in-moisture concentration equal to that of the brining solution. The initial moisture content of the cheese is assumed to be uniform and is denoted $W_{i}$.

The functional forms for the dependence of the diffusion coefficient on porosity (free moisture), and the dependence of pore space on bound water must also be decided. Curve-fitting to determine diffusion coefficients from experimental data suggests that the diffusion coefficient depends linearly on the porosity [15] 
and this is the form that is used here. Taking $\mathrm{D}^{\infty}$ as the porous diffusion coefficient for a cheese with reference porosity $\varepsilon_{r}$, the form of the diffusion coefficient is then

$$
\mathrm{D}(\varepsilon)=\mathrm{D}^{\infty} \frac{\varepsilon}{\varepsilon_{\mathrm{r}}} .
$$

Here $\varepsilon_{\mathrm{r}}$ is simply a reference porosity chosen to represent an 'average' cheese such that $\mathrm{D}^{\infty}$ is simply the porous diffusion coefficient for salt in the cheese matrix. For simplicity, the contraction effect is here taken to be linear - that is, the decrease in pore space is directly proportional to the decrease in the present amount of bound moisture. Complete extraction of bound moisture does not cause the cheese to contract so much that it completely excludes porous moisture - although brined cheeses do form a harder rind on their outsides, this rind is not completely moisture free [9] nor impermeable to salt [15], implying porous moisture remains. This 'base' amount of pore moisture is a property of the cheese and other conditions such as temperature, and is here denoted $\varepsilon_{0}$, leading to the expression relating pore moisture and bound moisture,

$$
\varepsilon=\varepsilon_{0}+k_{2} w .
$$

Under these conditions and assumptions, the system to be solved becomes

$$
\begin{aligned}
\frac{\partial C}{\partial t} & =\frac{\partial}{\partial y}\left(D^{\infty} \frac{\varepsilon_{0}+k_{2} w}{\varepsilon_{r}} \frac{\partial C}{\partial y}\right) \\
\frac{\partial w}{\partial t} & =\mu\left(w_{0}-k_{1}\left(\varepsilon_{0}+k_{2} w\right) C-w\right) w
\end{aligned}
$$

subject to boundary conditions

$$
\mathrm{C}(0, \mathrm{t})=\mathrm{C}_{0},\left.\quad \frac{\partial \mathrm{C}}{\partial \mathrm{y}}\right|_{\mathrm{y}=\frac{\mathrm{L}}{2}}=0
$$

and initial conditions

$$
C(y, 0)=\left\{\begin{array}{ll}
c_{0}, & y=0, \\
0, & 0<y \leqslant \frac{L}{2},
\end{array} \quad w(y, 0)=w_{i}=\frac{W_{i}-\varepsilon_{0}}{k_{2}+1} .\right.
$$


By trivially rearranging equation (16) it can be seen that for a given salt-inmoisture concentration $\mathrm{C}$ at some location within the cheese, this implementation of osmosis suggests that the amount of bound water will approach the steady state value of

$$
w^{*}= \begin{cases}\frac{w_{0}-k_{1} \varepsilon_{0} C}{k_{1} k_{2} C+1}, & C<\frac{w_{0}}{k_{1} \varepsilon_{0}}, \\ 0, & C \geqslant \frac{w_{0}}{k_{1} \varepsilon_{0}} .\end{cases}
$$

Of course the salt-in-moisture concentration itself will also be changing, but given that osmosis here depends on the available amount of pore space, it is important to determine how exactly the choice of $\varepsilon(w)$ made here (equation (14)) affects the behaviour of the bound moisture.

\subsection{Results}

The equations (15)-(16), subject to conditions (17) and (18) were solved numerically using a method of lines approach implemented in MATLAB [13] (ode15s), the partial differential equation (PDE) system converted to an ordinary differential equation (ODE) system by using a simple finite difference for the diffusion term in equation (15). Parameters used for simulations are listed in Table 6.

The salt and moisture profiles predicted by the model are visualised in Figure 6, demonstrating the invasion of salt into the cheese moisture over time, and the corresponding reduction of moisture in the cheese due to osmosis and shrinkage. Away from the edge exposed to the brining solution, the present amounts of salt and moisture asymptote towards their initial values, as expected [11]. The extent of salt penetration for this brining timeframe is realistic, qualitatively matching for example experimental data for the unidirectional brining of Romano-type cheese [10].

The overall effect of brining on the cheese is calculated by averaging the moisture and salt concentrations across the problem domain, with the overall 
Figure 6: Salt-in-moisture and moisture profiles for various brining times, with a cheese of initial moisture content $43 \%$ and a $20 \% \mathrm{NaCl}$ brining solution.
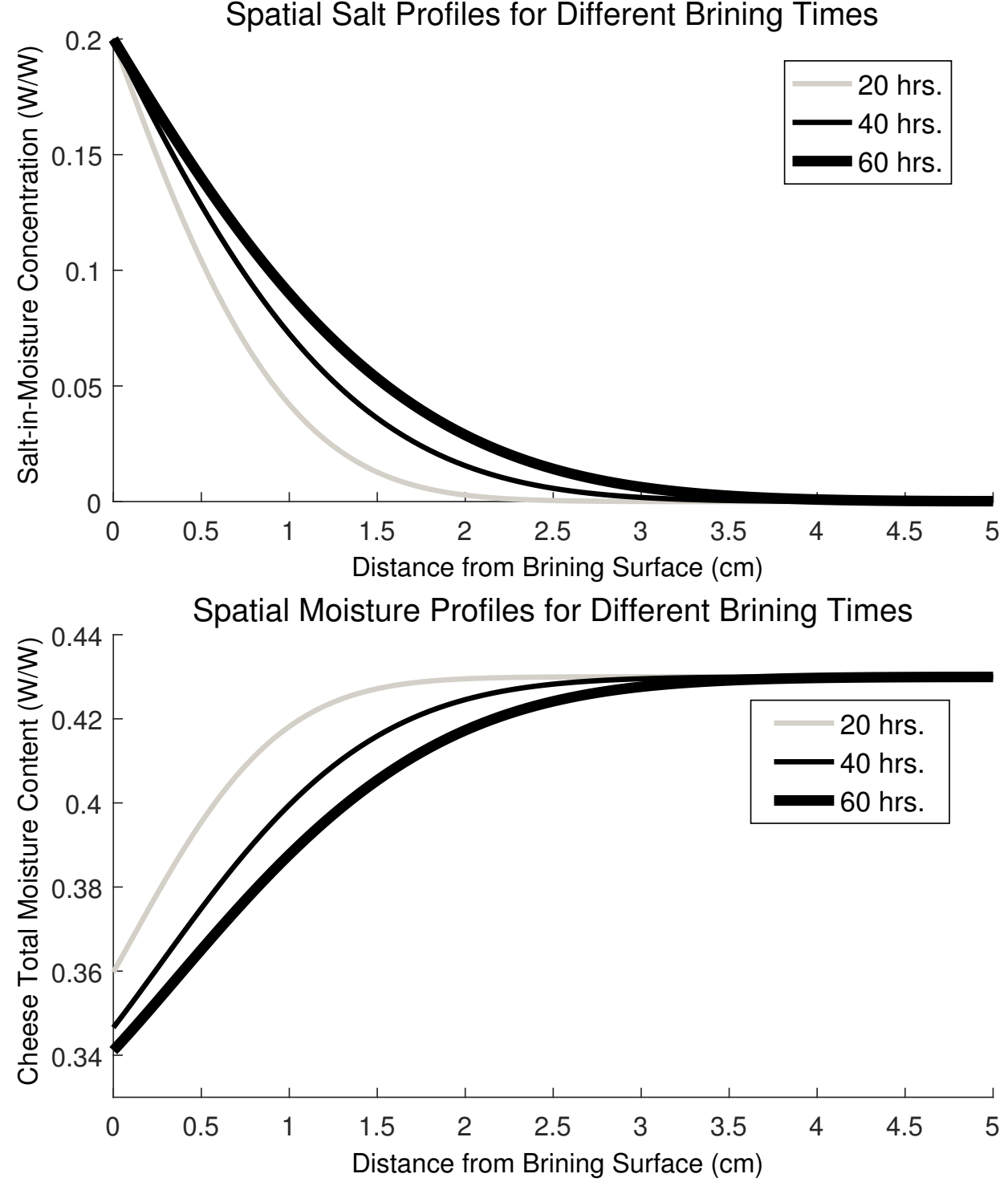
Table 6: Parameter values used in the presented numerical simulations of equations (15)-(16).

\begin{tabular}{llc}
\hline Parameter & Meaning & Value \\
\hline $\mathrm{D}^{\infty}$ & Impeded porous diffusion rate & $1.67 \times 10^{-2} \mathrm{~cm}^{2} / \mathrm{hr}$ \\
$\mu$ & Osmosis Rate & $5 / \mathrm{s}$ \\
$\mathrm{k}_{1}$ & $\begin{array}{l}\text { Osmotic pressure balance coeffi- } \\
\text { cient }\end{array}$ & $0.25 \mathrm{gH}_{2} 0 / \mathrm{gNaCl}$ \\
$\mathrm{k}_{2}$ & $\begin{array}{l}\text { Porosity change due to bound } \\
\text { water present }\end{array}$ & 5 \\
$\varepsilon_{0}$ & $\begin{array}{l}\text { Minimum free water amount/ } \\
\text { porosity }\end{array}$ & $0.75 \times \mathrm{W}_{\mathrm{i}}$ \\
$\varepsilon_{\mathrm{r}}$ & $\begin{array}{l}\text { Reference free water amount/ } \\
\text { porosity }\end{array}$ & 0.43 \\
\hline
\end{tabular}

salt concentration at each point calculated by multiplying the salt-in-moisture concentration by the amount of free moisture present. Calculating an average like this depends on what length of the problem domain is chosen, and comparison with brined cheese data must be performed with care because of the one-dimensional nature of this model, given the salt infiltration from all surfaces in three dimensions that actually occurs in practise. However, by choosing the halfway point $(y=L / 2)$ as the distance halfway along the shortest dimension of a rectangular block of cheese $(\mathrm{L} / 2=5 \mathrm{~cm})$, the amount of 'edge effects' caused by the three-dimensional nature of the problem are minimised, especially if the salt does not penetrate too deeply into the cheese. This allows the predictions of this model to be compared with overall salt and moisture content changes during the brining process observed in Fonterra's data (Table 7). Consideration of the total salt concentration, as opposed to the spatial profile of the salt-in-moisture concentration, is important not only for comparison with Fonterra's data but also because during the subsequent maturation process the salt further diffuses through the cheese via a slower process of movement through the cheese (and not just the cheese moisture) itself [9]. 
Table 7: Predicted final salt and moisture levels from Osmosis model, compared with actual values from measurements by Fonterra.

\begin{tabular}{lllll}
\hline $\begin{array}{l}\text { Brine } \\
\text { time } \\
\text { (hours) }\end{array}$ & $\begin{array}{l}\text { Predicted } \\
\text { Moisture \% }\end{array}$ & $\begin{array}{l}\text { Predicted } \\
\text { Salt \% }\end{array}$ & $\begin{array}{l}\text { Moisture } \\
\text { Relative } \\
\text { Error \% }\end{array}$ & $\begin{array}{l}\text { Salt Rel- } \\
\text { ative Er- } \\
\text { ror \% }\end{array}$ \\
\hline 49.50 & 41.71 & 1.49 & 3.34 & 7.78 \\
49.50 & 41.79 & 1.50 & 2.92 & 9.21 \\
50.25 & 41.48 & 1.49 & 2.62 & 2.23 \\
50.25 & 41.56 & 1.50 & 3.18 & 1.84 \\
51.30 & 41.34 & 1.50 & 2.94 & 1.39 \\
51.30 & 41.65 & 1.52 & 3.73 & 1.48 \\
58.83 & 40.99 & 1.59 & 4.86 & 5.77 \\
58.83 & 40.41 & 1.55 & 3.39 & 2.31 \\
63.28 & 41.33 & 1.67 & 1.01 & 3.08 \\
63.28 & 41.98 & 1.71 & 3.39 & 1.00 \\
\hline
\end{tabular}

The predictions of the osmosis model together with errors relative to Fonterra's data are presented in Table 7. Even without careful selection of functional forms for the effects of osmosis and the porosity change in response to shrinkage, the model performs quite well, especially in the case of longer-term brines. It is seen that even though each piece of cheese will be different in terms of relative contents of fat, protein and moisture, and $\mathrm{pH}$, the osmosis model successfully predicts the total amounts of salt and moisture after brining to within $10 \%$ in all cases for the given dataset (Table 7). The moisture is consistently over-estimated here, suggesting that more careful tweaking of parameters or functional forms could further improve the predictive power of the model. Consideration of the 3D nature of the cheese, and the existing small concentration of salt in the cheese block before brining are also important extensions to the model.

One of the most important factors in relation to production efficiency is the amount of salt introduced into a cheese for a given brining time, $t$. 
Luna and Chavez [11] and Guinee [9] state that the dependence of salt uptake on the brining time can be represented by $\sqrt{t}$, due to the process being governed by porous diffusion, and that this sort of trend can also be expected in practise [8]. The osmosis model uses porous diffusion as the sole transport mechanism of salt, with the addition of porosity changes that can disrupt this $\sqrt{t}$ behaviour.

Figure 7 demonstrates how the osmosis model predicts salt absorption to vary with brining time, and by additionally plotting the squared amount of salt it can be seen that the $\sqrt{t}$ dependence (represented by a straight line on such a graph) is achieved by this model after an initial settling period. However, this initial period does shift the intercept of the graph, and thus when the square root is taken the functional form of the salt content with time is slightly different:

$$
S=\sqrt{\beta_{0}+\beta_{1} t} .
$$

We reiterate that this equation only captures the long-term behaviour of the model (brining times greater than 20-25 hours); the brining times used by Fonterra do indeed easily exceed this threshold. The parameters $\beta_{0}$ and $\beta_{1}$ are linear regression parameters obtained from the straight-line portion of the graph of the squared salt content. For the cheese used to plot Figure 7, the values of these constants are $\beta_{0}=2.1 \times 10^{-5}$ and $\beta_{1}=4.6 \times 10^{-6}$. The fit provided by equation (20) is visualised in Figure 8.

The effect of the initial amount of moisture in the cheese on the amount of salt taken up by the cheese was found to vary nonlinearly, in a similar fashion to the interstitial diffusion model. However, across the range of realistic initial moisture contents (40-45\%), the dependence was found to be essentially linear. Unfortunately the proportionality constant was found to vary for different brining times, disallowing the incorporation of this linear effect into equation (20) in order to allow it to also capture the effects of different moisture concentrations in the cheese. 
Figure 7: Demonstration of the dependence of total salt content of the cheese on the total brining time (left), and the establishment of a $\sqrt{t}$-like behaviour after an initial settling period (right). In both cases the initial moisture content of the cheese is $43 \%$, with other parameters as listed in Table 6 .
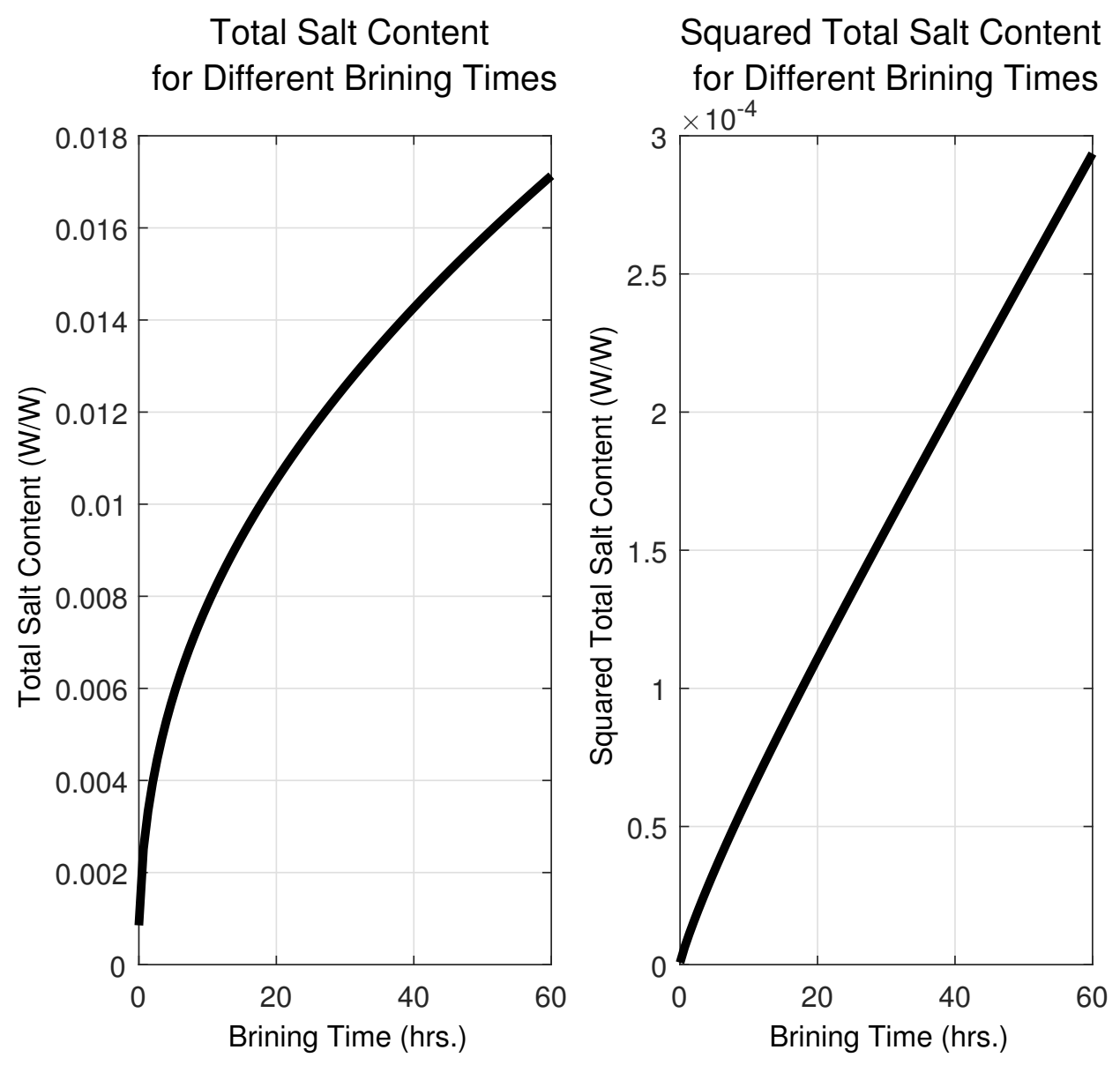
Figure 8: Comparison between the model (15)-(16) and the predictor of its long-term behaviour, equation (20), demonstrating the effectiveness of this simple relationship for total salt absorbed during the brining process.

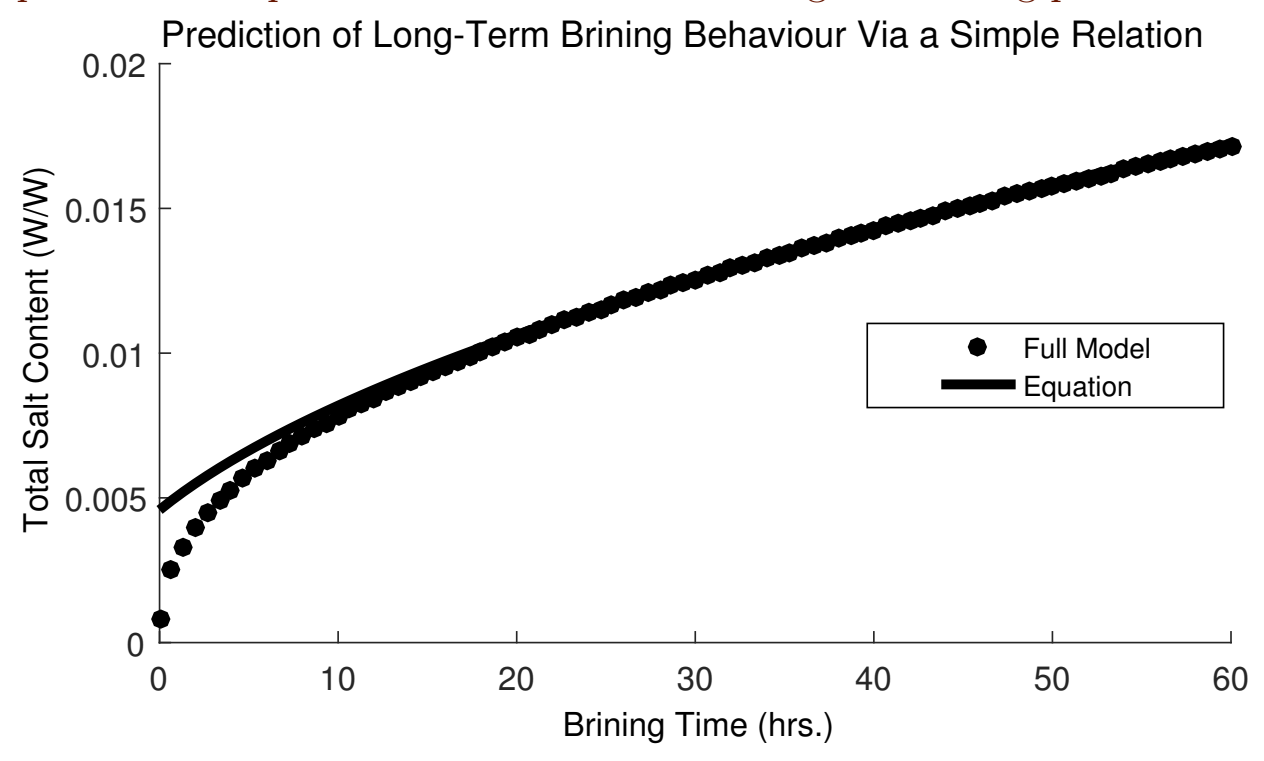

\subsection{Conclusions}

The invasion of salt into cheese via its porous cheese matrix has been modelled here using an approach which does not explicitly consider the movement of water during the brining process, but instead only the local effects of the osmotic pressure induced by salt in the cheese moisture and the subsequent shrinkage that salting of cheese is known to produce. Even without directly considering any diffusion or flow of water, realistic salt and moisture profiles have been achieved, including good agreement with Fonterra's data (less than $10 \%$ relative error for a range of data from long-term brines). Not explicitly modelling the flow of water through the cheese is beneficial because it allows ionic and spatial effects to be ignored - although diffusion for cheese moisture has been used to successfully model moisture changes during brining ([8, 
e.g.], or the interstitial diffusion model), and the importance of incorporating ionic effects has also been demonstrated [15]. However, the osmosis model presented here does have its own weaknesses, including the choice of linear relationships between variables (such as equation (14)) for simplicity where the real effects are presumably more complex, and might need to be determined empirically to improve realism and agreement with experimental data. Other natural extensions to this model include multiple spatial dimensions and a less phenomenological representation of osmosis.

A simple relationship (equation (20)) has been proposed as successfully predicting the long-term brining behaviour in cheese when the porosity changes that result from reduction in cheese moisture are taken into account. This is because equation (20) provides very good agreement with the osmosis model, which itself has shown good agreement with brining data. The proposed relationship is similar to the $\sqrt{t}$ dependence arising from linear diffusion which is well-known [8], but features two parameters which depend on properties of the cheese (including, importantly, its initial moisture content). From personal communication, Fonterra's current procedure is to keep the cheese in the brine until the desired composition has been reached. If left too long, then a hard rind develops on the surface where equation (20) implies that the invasion of salt can still continue. Some, but indeed not all porosity is lost at the edge of the cheese as the rind forms [15]. The recommendation here is for Fonterra to use long-term brining data to establish approximate values of $\beta_{0}$ and $\beta_{1}$ in equation (20) which offers a rough prediction of 'overall' variation of salt with brining time across many cheeses (which all have different initial moisture contents and other varying properties) in order to predict what sort of minimum brining time should be needed in order to consistently obtain cheeses with an overall salt content that meets their requirements. 


\section{Salt up-take model}

This model considers the possibility that an irreversible reaction takes place when salt binds to the cheese matrix. Salt from the brine bath is assumed to diffuse through the cheese, as in the earlier models, but now also reacts with the cheese matrix. When this reaction occurs, the cheese is said to have become 'salted'. In order to account for this effect, we introduce a new variable, $0 \leqslant \mathrm{~m} \leqslant 1$, which gives a measure of cheese salting. Cheese is assumed to be unsalted when it enters the brine bath $(m=0)$, and when all available salt binding sites are occupied, we have $m=1$. Alternatively, it might be viewed as the salted cheese matrix fraction.

\subsection{Governing equations}

In this model, we concentrate on salt transport, and this cheese-salt reaction, and neglect the changes in moisture content. For simplicity, we again consider a one-dimensional geometry. We denote the unbound salt concentration by $\mathbf{c}$, and assume that salt diffuses through cheese with diffusion coefficient $\mathrm{k}_{\mathrm{m}}^{*}$, which in general depends on the degree of salt binding to cheese matrix (i.e., $k_{m}^{*}$ may depend on $m$ ). The cheese takes up salt at a rate which depends on the number of available salt binding sites $(1-m)$ and the unbound salt concentration, the constant of proportionality being denoted $\xi$. The salt up-take process results in a proportional decrease in the unbound salt concentration. Our governing equations are thus

$$
\begin{aligned}
& \frac{\partial c}{\partial t}=k_{m}^{*}(m) \frac{\partial^{2} c}{\partial y^{2}}-\gamma \xi(1-m) c \\
& \frac{\partial m}{\partial t}=\xi(1-m) c
\end{aligned}
$$

where the constant $\gamma$ is a measure of the change in salt concentration which occurs when the cheese absorbs salt. The form of our governing equations is the same as that for a model for the aggregate alkali reaction in concrete [4]. 
We assume that, initially, the cheese block contains no salt, and hence our initial conditions are

$$
\mathrm{m}=\mathrm{c}=0 \quad \text { at } \mathrm{t}=0 .
$$

The concentration of salt in the brine bath is assumed to be kept constant, whilst the cheese block is assumed to be symmetric about the plane $y=\mathrm{L} / 2$. We thus impose the boundary conditions

$$
\begin{gathered}
c=c_{0} \quad \text { at } y=0, \\
\frac{\partial c}{\partial y}=0 \quad \text { at } y=\frac{L}{2} .
\end{gathered}
$$

Finally, we must specify the form of the diffusion coefficient $k_{m}^{*}(m)$. For simplicity, we can take $k_{m}^{*}=k_{m}=$ constant. However, alternative forms such as $k_{m}^{*}(m)=k_{m} e^{-\alpha m}$ (where $k_{m}, \alpha \geqslant 0$ are constants) are potentially worth considering; this particular choice would correspond to increasing salt-matrix binding resulting in reduced salt diffusion.

\subsection{Preliminary results}

Figure 9 shows preliminary results obtained from the salt up-take model, where we nondimensionalised equations (21) and (22). The left-hand boundary is in contact with the brine at a constant salt concentration, and salt diffuses from left to right through the cheese as time progresses. As the salt diffuses, it is absorbed by the cheese, thereby reducing the available sites for salt absorption. For the results shown here, approximately $40 \%$ of the cheese is fully salted at the end of the brining time, in that it cannot absorb any more salt. We set $k_{m}^{*}(m)=k_{m} e^{-\alpha m}$ in this case, and we see from Figure 9 that the rate of salt intrusion decreases as more of the cheese becomes salted.

These results qualitatively agree with the results of the previous two models. However, while this model has merit it requires further investigation to be able to obtain meaningful results for the cheese brining process. Some questions 
Figure 9: Dimensionless results from the salt uptake model for salt concentration, $\mathrm{C}$, and salt up-take fraction $\mathrm{m}$.
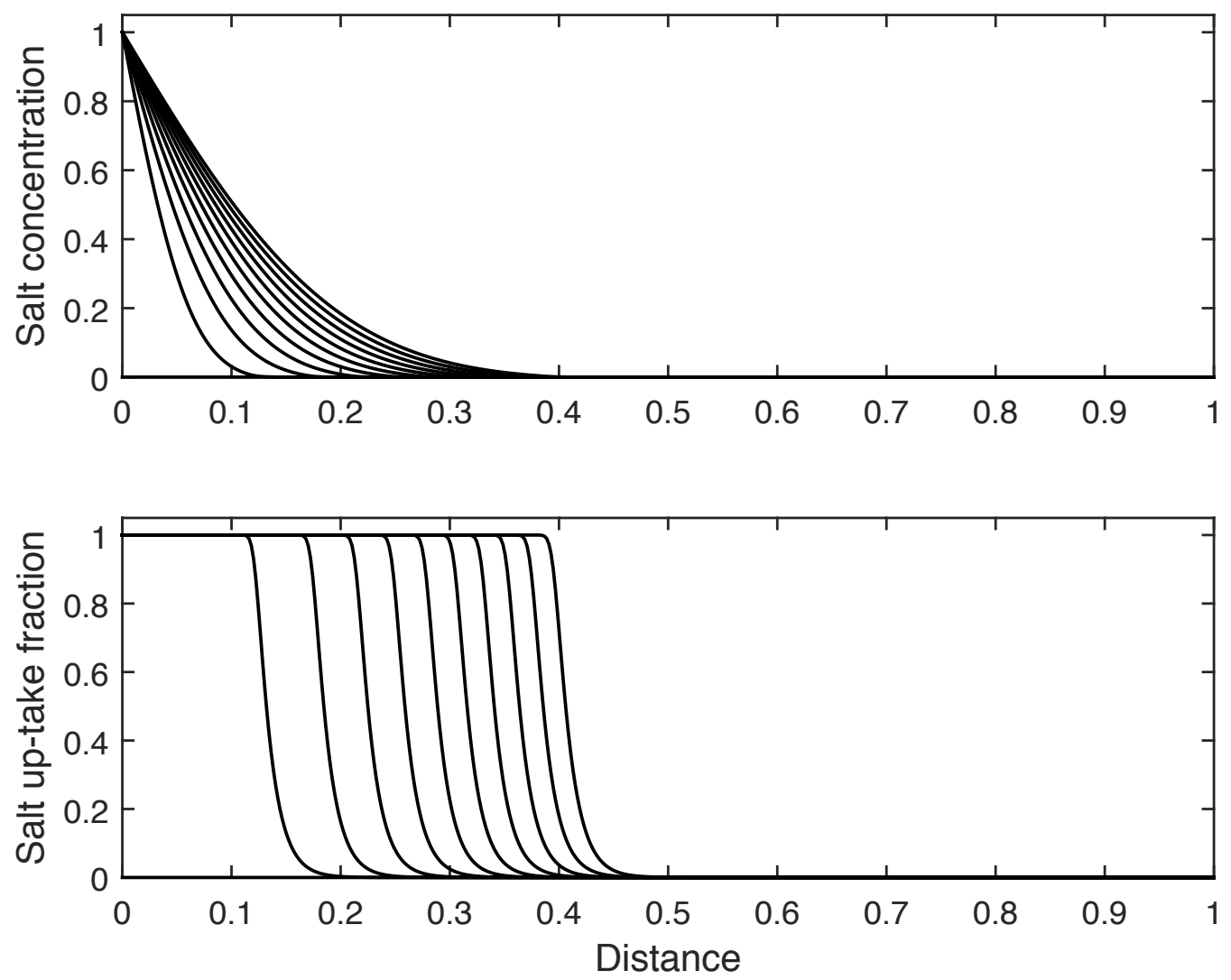
that need further consideration relate to the effect of moisture on salt diffusion, as different initial moisture contents have been observed to give different salt content for the same brine time; the reversibility of the binding of salt to the cheese matrix; and the equilibration of the salt content during the ripening stage after brining.

Fonterra [7] indicated that if a cheese block is taken from the brine solution and placed in pure water, the salt that had entered the cheese block would be free to diffuse out into the water due to the concentration gradient that exists. In the model given by equations (21) and (22), once the salt is bound to the cheese matrix it cannot be released. The reaction could be reversed by modifying $\xi$ in equations (21) and (22); however, the reaction is not able to spontaneously reverse direction by simply changing the boundary conditions. An alternative form of reaction such as adsorption may be more useful as it is readily reversible depending on the conditions that exist within the cheese. This is something that will be investigated in future work.

Additionally, depending on the choice of $k_{m}^{*}(m)$, once the brining has completed the diffusion of salt may be so impeded that no salt can continue to penetrate to the centre of the cheese block. This would result in a region of high salt content near the cheese boundary that will not dissipate during the ripening stage.

\section{Discussion}

The work conducted during the week of MISG2014 focused on three mathematical models investigating the processes that occur during cheese brining. The interstitial diffusion model was the most developed, and produced results that qualitatively agreed with data available from Fonterra and previous research $[8,14]$. The predicted moisture content gave good agreement with the data provided by Fonterra, and while there was considerable discrepancy in the predicted salt content of the cheese, we have shown that more accurate 
predictions are made through modifications to the salt diffusivity and partial molar volume, $\mathrm{D}_{\mathrm{C}}^{\infty}$ and $\bar{v}_{\mathrm{C}}$ respectively.

The second model investigated during MISG2014 was termed the osmosis model. This model considers moisture in the cheese to be either free moisture available for salt diffusion, or bound water held by the cheese protein. It assumes that salt is able to diffuse through the moisture; however, the moisture only moves due to the salt - there is no diffusion of moisture. The osmosis model was able to obtain very good agreement with the data provided by Fonterra, with relative errors less than $5 \%$ and $10 \%$ for predicted moisture and salt content respectively.

For both the interstitial diffusion and osmosis models, additional work should be conducted on calculating porosity or shrinkage from the up-take of salt. Pore shrinkage is a main component in these first two models, and while dissolving salt in water does not significantly change its volume, as the salt is absorbed by the cheese it leads to significant textural changes [8]. However, both of these models are currently able to give good agreement to the data, indicating that they could be used to develop a look-up table of brining times for a given initial moisture content and desired salt content.

The salt up-take model considers a reaction-diffusion process describing the transport of salt while ignoring the effect of moisture in the cheese. In the current form, salt is bound to the cheese matrix, and once bound is unable to be removed. This model requires additional investigation to be more applicable to the brining of cheese. The effect of moisture on the rate of salt uptake should be included, as it is recognised that the moisture content can greatly affect the salt content post-brining. Additionally, further investigation is needed on alternatives to the reaction, equations (21) and (22). One possibility is the use of an adsorption reaction to describe salt being bound to the cheese matrix. An adsorption process has the advantage of being able to occur in both directions (salt can be bound and unbound) depending on the salt concentration in the cheese. 
Acknowledgements This research is supported by the Primary Growth Partnership scheme sponsored by Fonterra Co-operative Group and the New Zealand Government. We thank the following for their helpful contributions to the work described: Mark Flegg, Jennifer Flegg, Qianqian Yang, Hayden Tronnolone, Alexandra Hogan, Louise Manitzky, Dylan Lusmore, Katrina Treloar, Megan Farquhar, James Reoch, Jannah Baker, Tony Gibb, Ayham Zaitonny, Kay Marion, Bill Whiten, Pamela Burrage, Alistair Fitt, Neville Fowkes.

\section{References}

[1] P. W. Atkins. Physical Chemistry. Oxford University Press, 4th edition, 1990. M64

[2] G. Aylward and T. Findlay. SI Chemical data. John Wiley and Sons, 1974. M66

[3] D. A. G. Bruggeman. Calculation of the various physical constants of heterogeneous substances. I: Dielectric constants and conductivities of mixtures of isotropic substances. Annalen der Physik, 25:636-664, 1935. doi:10.1002/andp.19354160705. M64

[4] G. Carey, N. Fowkes, A. Staelens, , and A. Pardhanani. A class of coupled nonlinear reaction diffusion models exhibiting fingering. Journal of Computational and Applied Mathematics, 166(1), 2004. doi:10.1016/j.cam.2003.09.037. M87

[5] R. Datta and S. A. Vilekar. The continuum mechanical theory of multicomponent diffusion in fluid mixtures. Chemical Engineering Science, 65:5976-5989, 2010. doi:10.1016/j.ces.2010.08.022. M62

[6] C. J. D. Fell and H. Hutchison. Diffusion coefficients for sodium and potassium chlorides in water at elevated temperatures. Journal of 
Chemical and Engineering Data, 16:427-429, 1971. doi:10.1021/je60051a005. M66

[7] Fonterra Co-Operative Group. Personal communication. 2014. M62, M63, M65, M66, M71, M72, M90

[8] T. J. Geurts, P. Walstra, , and H. Mulder. Transport of salt and water during salting of cheese. 1: Analysis of the processes involved. Netherlands Milk and Dairy Journal, 28:102-129, 1974. M71, M77, M83, M86, M90, M91

[9] T. P. Guinee. Salting and the role of salt in cheese. International Journal of Dairy Technology, 57(2):99-109, 2004. doi:10.1017/S0022112003005512. M59, M61, M62, M74, M78, M81, M83

[10] T. P. Guinee and P. Fox. Sodium chloride and moisture changes in romano-type cheese during salting. Journal of Dairy Research, 50:511-518, 1983. doi:10.1017/S002202990003274X. M77, M79

[11] J. A. Luna and M. S. Chavez. Mathematical model for water diffusion during brining of hard and semi-hard cheese. Journal of Food Science, 57:55-58, 1992. doi:10.1111/j.1365-2621.1992.tb05423.x. M77, M79, M83

[12] K. Mandl, R. W. Hartel, and W. Wendorff. Effects of moisture and salt migration on cheese firmness in cheese-in-sausage products. Journal of Food Engineering, 91:164-172, 2009. doi:10.1016/j.jfoodeng.2008.08.022. $\mathrm{M} 62$

[13] MATLAB. version 8.1 (R2013a). The MathWorks Inc., Natick, Massachusetts, 2013. M66, M79

[14] W. Messens, K. Dewettinck, and A. Huyghebaert. Transport of sodium chloride and water in gouda cheese as affected by high-pressure brining. International Dairy Journal, 9:569-576, 1999. doi:10.1016/S0958-6946(99)00126-0. M71, M90 
[15] M. R. Payne and K. R. Morison. A multi-component approach to salt and water diffusion in cheese. International Dairy Journal, 9:887-894, 1999. doi:10.1016/S0958-6946(99)00157-0. M61, M62, M76, M77, M78, M86

[16] M. Turhan and G. Kaletunç. Modeling of salt diffusion in white cheese during long-term brining. Journal of Food Science, 57:1082-1085, 1992. doi:10.1111/j.1365-2621.1992.tb11269.x. M76

[17] H. Weingärtner. Self-diffusion in liquid water. A reassessment. Zeitschrift fur Physikalische Chemie, 132:129-149, 1982. doi:10.1524/zpch.1982.132.2.129. M66

\section{Author addresses}

1. S. T. P. Psaltis, School of Mathematical Sciences, Queensland University of Technology, Brisbane, Qld 4000, Australia. mailto:steven.psaltis@qut.edu.au

2. J. E. F. Green, School of Mathematical Sciences, University of Adelaide, South Australia, 5005, Australia. mailto: edward.green@adelaide.edu. au

3. T. W. Farrell, School of Mathematical Sciences, Queensland University of Technology, Brisbane, Qld 4000, AUstralia. mailto:t.farrell@qut.edu.au

4. B. Lawson, School of Mathematical Sciences, Queensland University of Technology, Brisbane, Qld 4000, Australia. mailto: brodie. lawson86@gmail. com

5. J. L. Simpson, Fonterra Co-operative Group Ltd, Hautapu, New Zealand. mailto: jo.simpson2@fonterra.com 